\title{
RESPONSE OF REINFORCED CONCRETE STRUCTURAL ELEMENTS TO NEAR-FIELD AND CONTACT EXPLOSIONS
}

\author{
E. ATHANASIOU ${ }^{1}$, F. TEIXEIRA-DIAS ${ }^{1}$, F. COGHE ${ }^{2} \&$ L. DESMARET ${ }^{3}$ \\ ${ }^{1}$ School of Engineering, The University of Edinburgh, UK \\ ${ }^{2}$ Royal Military Academy, Belgium \\ ${ }^{3}$ Department R\&D-Ballistic Analysis-Mecar S.A., Belgium
}

\begin{abstract}
The integrity of buildings and the safety of their occupants can be catastrophically affected by the action of contact or near-field explosions. Numerical simulation studies should be carried out in order to better understand the response of reinforced concrete (RC) structures to such dynamic impulsive actions. When concrete structural elements are subjected to near-field blast loads, large deformations, rate effects and overloading render the modelling of concrete extremely complex. Significant research has been done since September 11, 2001, in order to improve the computational abilities, to understand the complex non-linear behaviour of concrete under extreme loading conditions and to obtain reliable numerical results. Simulations can be done using 'user-developed' codes or commercial hydrocodes. One of the most common hydrocode is LS-DYNA, where concrete can be treated as a homogeneous material. In this particular project LS-DYNA is used along with the Winfrith Concrete Model to simulate the response of a two-layer RC slab to several contact detonations (using C4, Composition-4). The aim is to achieve a contact explosion between the target (slab) and the explosive since literature can provide us with only limited information regarding this. The slab and the high explosive are explicitly modelled using the multi-material arbitrary Lagrangian-Eulerian approach (MM-ALE). The obtained numerical results are validated using experimental data. The aforementioned numerical results of the damage are in favourable agreement with the experimental data, with average errors lying under $10 \%$. In addition, it was observed that the increase in the explosive mass led to a change of the damage mode from penetration to perforation. Concrete's crack pattern was also investigated.

Keywords: blast, contact explosion, finite element analysis, near-field explosion, numerical modelling, reinforced concrete, structural elements.
\end{abstract}

\section{INTRODUCTION}

Explosions are high transient dynamic events where overloading, rate effects and large deformation take place due to the rapid release of energy. Based on the way in which this energy is released, explosions can be classified as physical, nuclear or chemical. Furthermore, the explosive material can be solid, gas or liquid and its sensitivity to ignition is responsible for the classification of the explosive as being primary or secondary. Most of the released energy is contained in a relatively thin layer of air under compression (blast wave) [1], which is responsible for the severe damage on the structure. A typical blast pressure profile as well as expressions regarding the maximum overpressure can be found in Tai et al. [2]. Hydrocodes that are most commonly used to capture the behaviour of concrete under those circumstances are AUTODYN [3] and LS-DYNA [4]. The stresses and strains are treated in the above codes separately in a volumetric and a deviatoric part. The volumetric part is governed by the 
equation of state (EOS), which relates the hydrostatic pressure with the local energy and density. The strength surface, defined by a strength criterion (e.g. Drucker-Prager, MohrCoulomb, William-Warnke five parameter criterion, Hsieh-Ting-Chen, Ottosen) governs the deviatoric part and shows the relationship between the first stress invariant $I_{1}$ and the second invariant of the deviatoric stress tensor $J_{2}$ and sometimes with the third deviatoric stress invariant $J_{3}$ [5]. Furthermore, the strength of the concrete is strain rate dependent. As the strain rate increases the strength of the concrete increases as well and the dynamic increase factor (DIF) is a parameter that can be used to represent this sensitivity. Bearing in mind that concrete exhibits different behaviour in tension and compression, the DIF should be able to capture this. Several material models have been developed and implemented in the referred finite element packages. They take into account the basic characteristics of material behaviour (e.g. strain hardening, pressure hardening, strain rate dependency) but they differ in some proposed assumptions [6]. In particular, in some material models the third deviatoric stress invariant $J_{3}$ is not considered or the DIF factor is the same for both tension and compression. The above explains the existence of a large number of material models. Each new model tries to recommend better parameters and to improve on the existing models. An important issue that is addressed here is to make a model parameterisation that reflects the actual non-linear dynamic behaviour of concrete under contact detonation.

\section{EXPERIMENTAL SET-UP}

In the present study, five RC square-shaped slabs with dimensions $850 \times 850 \times 70\left[\mathrm{~mm}^{3}\right]$ were tested in the laboratories of the Royal Military Academy (Belgium) under contact explosion. The explosive charge was placed at zero standoff distance. The experimental work has been conducted to obtain data for validation through numerical simulation using the finite element analysis software LS-DYNA.

Concrete slabs were reinforced with a two-layer steel mesh with $20 \mathrm{~mm}$ concrete cover, each mesh consisting of $6 \times 6$ steel bars with a $5 \mathrm{~mm}$ diameter and $150 \mathrm{~mm}$ spacing from centre-to-centre. The reinforcement yield strength was $469 \mathrm{MPa}$, the density $7890 \mathrm{~kg} / \mathrm{m}^{3}$ and the elastic modulus $205 \mathrm{GPa}$. The concrete that was used for the preparation of the slabs had an average 28-day compressive strength of $45 \mathrm{MPa}$, a tensile strength of $5 \mathrm{MPa}$, a density of $2370 \mathrm{~kg} / \mathrm{m}^{3}$ and an elastic modulus of $33.5 \mathrm{GPa}$.

Composition-4 (C4) was chosen as the plastic explosive. This high explosive is extensively used in industrial and military applications. Its chemical name is cyclotrimethylenetrinitramine $\left(\mathrm{C}_{3} \mathrm{H}_{6} \mathrm{~N}_{6} \mathrm{O}_{6}\right)$ and it is commercially known as RDX (Royal Demolition Explosive or Research Development Explosive). C4 has a higher specific energy than TNT. For modelling purposes an equivalent mass of TNT is required as an input, which means that the mass of $\mathrm{C} 4$ should be multiplied by a converting factor of 1.37 [7].

Five identical RC slabs were tested under the contact explosion of 75, 50, 25, 15 and $10 \mathrm{~g}$ of $\mathrm{C} 4$. The explosive was positioned at the centre of the slabs, which were supported on steel frames.

\section{NUMERICAL MODELLING}

\subsection{General approach}

The commercial explicit FEA package LS-DYNA was used for its potential in modelling highly transient problems. For dynamic phenomena such as blast loading, LS-DYNA utilises explicit time integration based on the central difference technique. Three different approaches can be used in LS-DYNA to simulate structures under blast loading: (i) load blast enhanced 


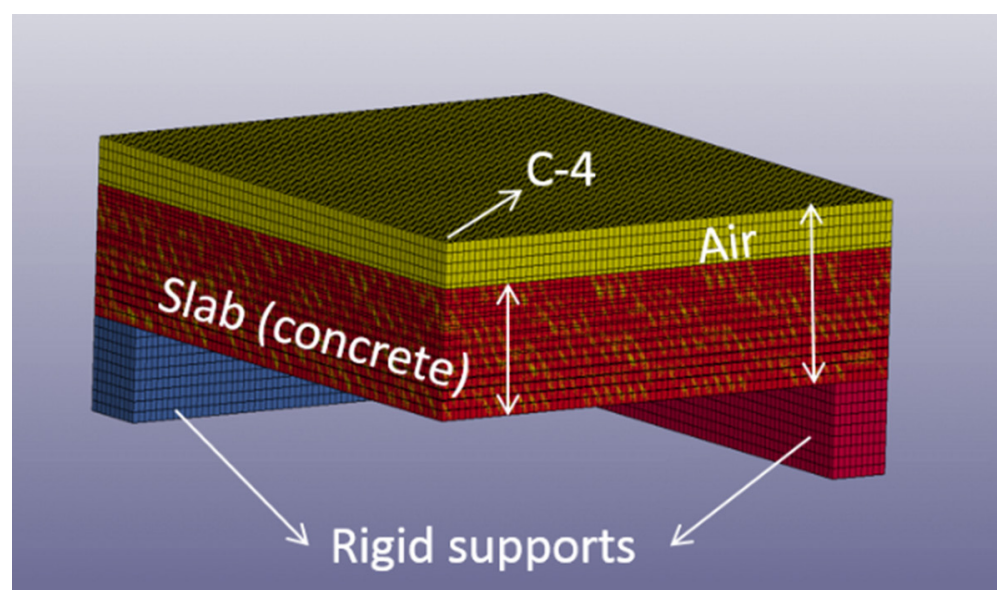

Figure 1: LS-DYNA finite element discretisation model.

(LBE), (ii) multi-material arbitrary Lagrangian-Eulerian (MM-ALE) and (iii) the coupling between these two [8]. The first is a Lagrangian approach, which means that the mesh and the structural material are moving together. The disadvantage of this method is that in large deformation events, elements may become too deformed, leading to a wrong solution. Using the MM-ALE technique, however, where the explosive charge and the air are separately modelled, it is assumed that the material flows through the mesh and that the elements can consist of multiple materials. In the present study, MM-ALE is used since it is a very attractive method for representing the flow of the gas from explosives under detonation [9]. The discretisation shown in Fig. 1 was achieved using two-plane symmetry (i.e. 1/4 of the slab, $425 \times$ $\left.425 \times 70\left[\mathrm{~mm}^{3}\right]\right)$ and solid hexahedra elements (size $h c=5.53 \mathrm{~mm}$ ) for the Lagrangian part (slab). Furthermore, the air was modelled using the same mesh size in a box with dimensions of $425 \times 425 \times(70+R) \mathrm{mm}^{3}$, where $R$ is the radius of the equivalent TNT charge. Knowing the mass of TNT and its density $\left(r=1600 \mathrm{~kg} / \mathrm{m}^{3}\right)$, the radius of the five different amounts of the explosive was determined.

\subsection{Contact algorithms}

There are three methods employed to include the reinforcement into the concrete slab and couple the two Lagrangian parts [10]. The first method is the smeared approach where the reinforcement bars are considered as a volume fraction of the steel and the concrete. The second is the explicit approach with shared nodes, where the nodes of the reinforcement and concrete are shared. The third method and the one that is used in the current work is the penalty approach, where the two meshes are developed individually using the same size of elements (solid hexahedra elements and beam elements for concrete and reinforcement, respectively). Then the rebars are embedded in the concrete slab, where perfect bonding is considered [2]. The same penalty method was used to couple the air and TNT of the Eulerian domain with the slab, which belongs to the Lagrangian domain.

\subsection{Boundary conditions}

The explosive is placed at the top edge of the slab and only $1 / 8$ of it is modelled due to symmetry. Every side of the slab next to the explosive is allowed to move on the directions of 
the side but the rotations are fixed for those directions. The air at the same sides follows the same boundary conditions. Modelling 1/8 of the explosive means that the top face of the air is fixed from moving upwards and downwards and the rotations on the other two directions are fixed as well. In addition, boundary non-reflecting conditions were chosen for the other two sides of air, which are away from the explosive. For the rigid material of the fixed at the bottom supports $\left(50 \times 50 \times 425\left[\mathrm{~mm}^{3}\right]\right)$ with $\rho=7830 \mathrm{~kg} / \mathrm{m}^{3}, E=207 \mathrm{GPa}$ and $v=0.3$, solid hexahedra elements and automatic surface-to-surface contacts were chosen.

\subsection{Damage criteria}

An erosion algorithm was implemented and used to represent the physical damage procedure $[11,12]$. This is a numerical technique where elements that have reached a limit strain value are deleted from the model. The purpose of doing this is that in conditions of large deformations, such as the blast wave effects, the Lagrangian mesh can assume non-physical deformations.

A wide range of erosion criteria exists and it is a known fact that numerical results are strongly influenced by the erosion criteria. Most of these criteria are based upon strain limitations. In the current work and after a convergence study, which showed that the strain value is mesh dependent, the equivalent strain $\varepsilon=0.001$ is used.

\subsection{Gaseous materials (explosive and air)}

\subsubsection{Equation of state (EOS)}

The Jones-Wilkins-Lee (JWL) EOS is adopted to model the high explosive [2,9]. The model determines the detonation time of the charge when the velocity $D$, the initial density $\rho_{0}$ and the pressure of detonation are known. The pressure that depicts the energy that is released can be given by the following equation:

$$
p=A\left(1-\frac{\omega}{R_{1} v}\right) e^{-R_{1} v}+B\left(1-\frac{\omega}{R_{2} v}\right) e^{-R_{2} v}+\frac{\omega E}{v}
$$

where $A, B, \omega, R_{1}, R_{2}$ are constants, $E$ is the energy per unit volume and $v=\rho_{0} / \rho$ is the relative volume (values are listed in Table 1). In addition, the EOS used for modelling the air is the following linear polynomial equation:

$$
p=C_{0}+C_{1} \mu+C_{2} \mu^{2}+C_{3} \mu^{3}+\left(C_{4}+C_{5} \mu+C_{6} \mu^{2}\right) E_{0}
$$

where $E_{0}=0.258 \mathrm{MPa}$ is the initial energy density, $\mu=\rho / \rho_{0}-1$ with $\rho$ and $\rho_{0}$ the current and the initial density of air $\left(\rho_{0}=1.23 \mathrm{~kg} / \mathrm{m}^{3}\right)$, and $C_{0}-C_{6}$ are coefficients. Air is assumed as an ideal gas with $C_{0}=C_{1}=C_{2}=C_{3}=C_{6}=0$ and $C_{4}=C_{5}=\gamma-1(\gamma=1.4)$.

Table 1: Material and EOS parameters for TNT.

\begin{tabular}{lcccccccc}
$\rho_{0}\left(\mathrm{~kg} / \mathrm{m}^{3}\right)$ & $D(\mathrm{~m} / \mathrm{s})$ & $P_{c j}(\mathrm{MPa})$ & $A(\mathrm{MPa})$ & $B(\mathrm{MPa})$ & $R_{1}(-)$ & $R_{2}(-)$ & $\omega(-)$ & $E_{0}(\mathrm{MPa})$ \\
\hline 1630 & 6930 & 21000 & $3.71 \mathrm{e}+5$ & $3.23 \mathrm{e}+3$ & 4.15 & 0.95 & 0.3 & 7000 \\
\hline
\end{tabular}




\subsubsection{Gaseous material models}

The Mat_HIGH_EXPLOSIVE_BURN card is used for the high explosive and Mat_NULL for the air; the latter allows the EOS to be applied without finding the deviatoric stresses and also permits air to behave like a fluid.

\subsection{Structural materials}

\subsubsection{Material model for the slab}

The Winfrith concrete material model has been used in the current study. This model was initially developed for the UK nuclear industry in the 1980s and, in 1991, was implemented in LS-DYNA [13]. The model considers the third stress invariant of the deviatoric stress tensor $\left(J_{3}\right)$, the elimination of the expansion of the material through radial return, non-compulsory consideration of rate effects, strain softening in tension through crack opening width, cracking of concrete material in tension with the limit of three orthogonal crack planes on each element and consideration of reinforcement within the model or explicitly. The deviatoric part describing the material's failure surface can be derived from the Ottosen criterion as follows [14]:

$$
F\left(I_{1}, J_{2}, \cos 3 \theta\right)=a \frac{J_{2}}{f_{c}^{2}}+\lambda \frac{\sqrt{J_{2}}}{f_{c}}+b \frac{I_{1}}{f_{c}}-1
$$

where $a$ and $b$ are internally generated constants that adjust the meridional shape and are affected by the ratio of the tensile to compressive strengths, $K_{1}$ and $K_{2}$ are functions of the same ratio and $\lambda$ shows the dependence on the $J_{3}$ invariant. The EOS that relates the pressure to the volumetric strain is either taken into consideration within the model or can be user defined. Concrete behaviour is known to be strain rate dependent as its static tensile and compressive strengths increase by a factor (DIF) when subjected to dynamic loading [15]. Rate effects were considered in this work. The coding in LS-DYNA for the Winfrith model follows the enhancement factors recommendations for tension and compression given by the Comité Euro-International du Béton [16].

\subsubsection{Material model for the reinforcing bars}

The reinforcing bars were assumed as beam elements with rate effects (viscoplastic formulation) and ductile behaviour after yielding. In addition, linear elastic performance was adopted before yield and plastic deformation along with strain hardening after yield.

\section{RESULTS AND DISCUSSION}

Numerical and experimental results of the observed damage from the front and the back side of the detonated slabs are presented in Table 2, along with the obtained errors, in order to prove that simulations can predict the experimental data in a very good manner. Furthermore, all the results will be discussed separately even though only images from the lower case $(10 \mathrm{~g})$ and upper case $(75 \mathrm{~g})$ are presented in Figs 2 and 3.

As shown in Fig. 2, under the detonation of $10 \mathrm{~g}$ of $\mathrm{C} 4$ the slab exhibited moderate damage both for the experiments and the numerical simulations. The medium class spallation that occurred in the experiments - very shallow penetration of $10 \mathrm{~mm}$ from the top and the bottom of the slab - perfectly matched the numerical spallation. Furthermore, the errors of damage for the front and the back side of the slab (10.6\% and 5.2\%, respectively) showed favourable agreement. 

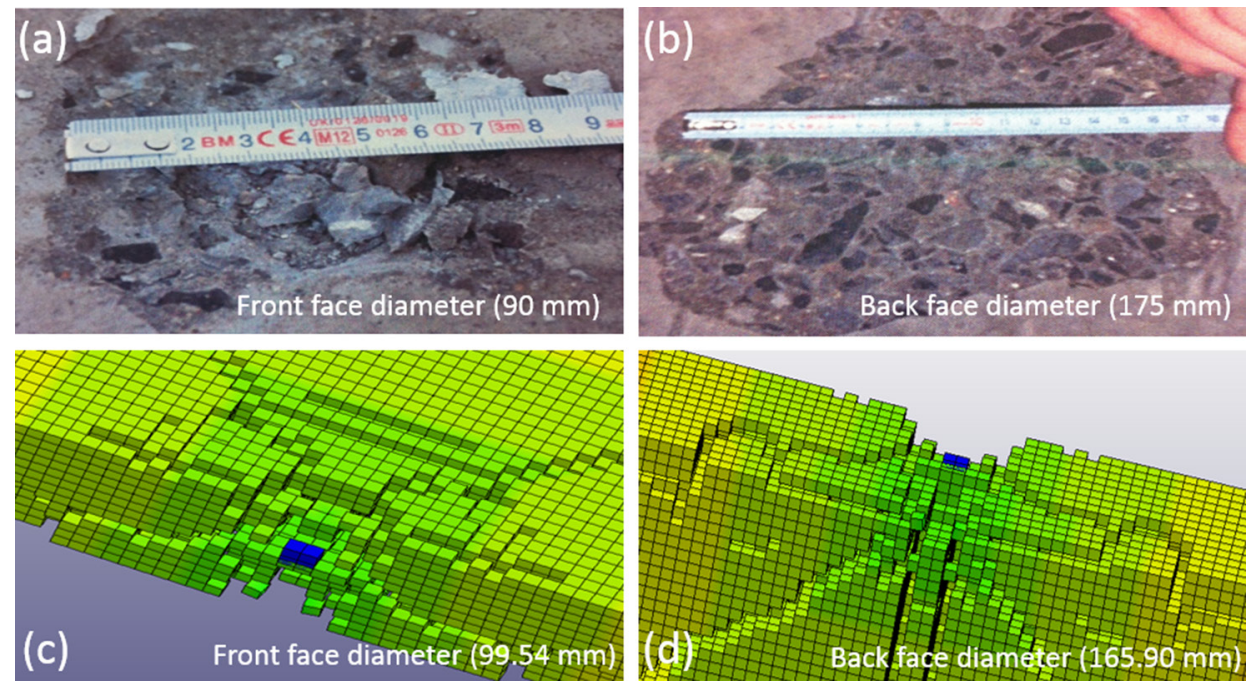

Figure 2: Damage caused by the detonation of $10 \mathrm{~g}$ of $\mathrm{C} 4$ : (a) and (b) experimental observations and (c) and (d) numerical results.
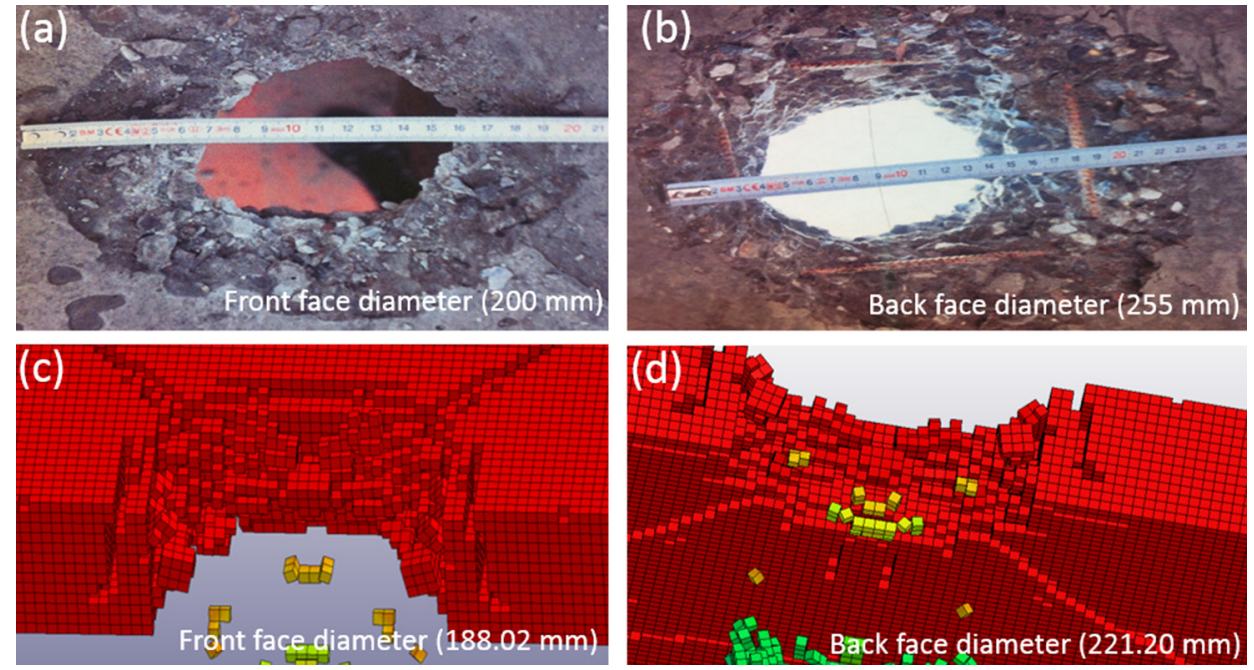

Figure 3: Damage caused by the detonation of $75 \mathrm{~g}$ of $\mathrm{C} 4$ : (a) and (b) experimental observations and (c) and (d) numerical results.

The slab under the detonation of $15 \mathrm{~g}$ of $\mathrm{C} 4$ showed again a moderate damage but with greater penetration due to the increase in the amount of the explosive. The experimental penetration was measured as 20 and $22 \mathrm{~mm}$ for the front and the back side of the tested slab respectively, while the numerical penetration was measured as 16.59 and $33.18 \mathrm{~mm}$ for the same sides. Although the error obtained in the upper side is too low $(6.4 \%)$, the numerical simulations for the lower side underestimate the damage, with an obtained error of $17.7 \%$.

The case of the $25 \mathrm{~g}$ of $\mathrm{C} 4$ explosion exhibited the threshold of high damage with evidence of total penetration (perforation). Comparison between experimental and numerical results 
predicts the damage at the front and back faces of the slab, with $6.5 \%$ and $13.4 \%$ errors, respectively. Additionally, high damage level combined with perforation can be observed after the detonation of $50 \mathrm{~g}$ of $\mathrm{C} 4$. Although the numerical prediction of the damage in the front side exhibited the best performance giving the lowest error among the other slabs $(0.5 \%)$, the error obtained at the back was slightly high (12.4\%), but again in an acceptable range.

The detonation of $75 \mathrm{~g}$ of $\mathrm{C} 4$ showed again that the numerical damage and the experimental damage were consistent. Both the experimental and numerical results (Fig. 3) exhibited high damage with perforation. In the front face of the slab, the predicted damage is very close to the experimental with a given error of $6.0 \%$. While at the back even though the numerical prediction of the diameter's damage is larger than the damage caused by the $50 \mathrm{~g}$, it still gives a slightly high error of $13.3 \%$ but again in an acceptable range.

The results in Table 2, show that the errors lie in the acceptable range of $6.50 \%$ to $10 \%$ except for the detonation of $15 \mathrm{~g}$ of $\mathrm{C} 4$ which slightly exceeds that value $(12.1 \%)$. Furthermore, the experiments showed that as the amount of the explosive is increased the damage increases as well. The numerical results are in favourable agreement with the above statement. In addition, comparing the errors obtained separately from the upper and lower side of the slabs on each detonation, we concluded that the numerical modelling predicted the damage more accurately at the front face of the detonated slabs than at the back side.

In terms of the crack pattern, Fig. 4 shows the crack propagation at the front face of all tested slabs. As the amount of $\mathrm{C} 4$ increases, diagonal cracks start from the centre of the specimens and expand to the corner. These cracks follow the yield line of a supported slab. Under $15 \mathrm{~g}$, no cracks were observed. When the explosive was increased to $25 \mathrm{~g}$ the first diagonal cracks were evident. The width of those was approximately $5.5 \mathrm{~mm}$. Under the detonation of 50 and $75 \mathrm{~g}$ these cracks were totally expanded to the corner and the width of those was increased to $10 \mathrm{~mm}$ approximately. The crack propagation can be observed in Fig. 5, along with the damage at the back face of all tested slabs. When the incident wave hits the upper face of each slab it acts as a compressive load. At the same time and as the detonation is in contact the reflected wave (tensile load) causes a bending failure at the back face of the slabs due to the concrete's low tensile strength. When the amount of the explosive increases, the slabs moved from bending failure to punching shear failure. Since the diameter of the whole at the top is smaller than the diameter at the back, we concluded that the concentrated forces from contact explosion induce a cone-shaped perforation through the thickness of the slabs (punching shear effect). In addition to that, the diagonal crack propagation continues

Table 2: Numerical and experimental measured diameters of the damaged slabs.

\begin{tabular}{lccccccc}
\hline & \multicolumn{3}{c}{ Front face diameter } & \multicolumn{3}{r}{ Back face diameter } & \multicolumn{2}{c}{ Average errors } \\
\cline { 2 - 8 } C4 (g) & $\begin{array}{c}\text { Experimental } \\
(\mathrm{mm})\end{array}$ & $\begin{array}{c}\text { Numerical } \\
(\mathrm{mm})\end{array}$ & $\begin{array}{c}\text { Error } \\
(\%)\end{array}$ & $\begin{array}{c}\text { Experimental } \\
(\mathrm{mm})\end{array}$ & $\begin{array}{c}\text { Numerical } \\
(\mathrm{mm})\end{array}$ & $\begin{array}{c}\text { Error } \\
(\%)\end{array}$ & $(\%)$ \\
\hline 10 & 90 & 99.54 & 10.6 & 175 & 165.90 & 5.2 & 7.9 \\
15 & 130 & 121.66 & 6.4 & 215 & 176.96 & 17.7 & 12.1 \\
25 & 135 & 143.78 & 6.5 & 230 & 199.08 & 13.4 & 10 \\
50 & 165 & 165.90 & 0.5 & 240 & 210.14 & 12.4 & 6.5 \\
75 & 200 & 188.02 & 6.0 & 255 & 221.20 & 13.3 & 9.6 \\
\hline
\end{tabular}



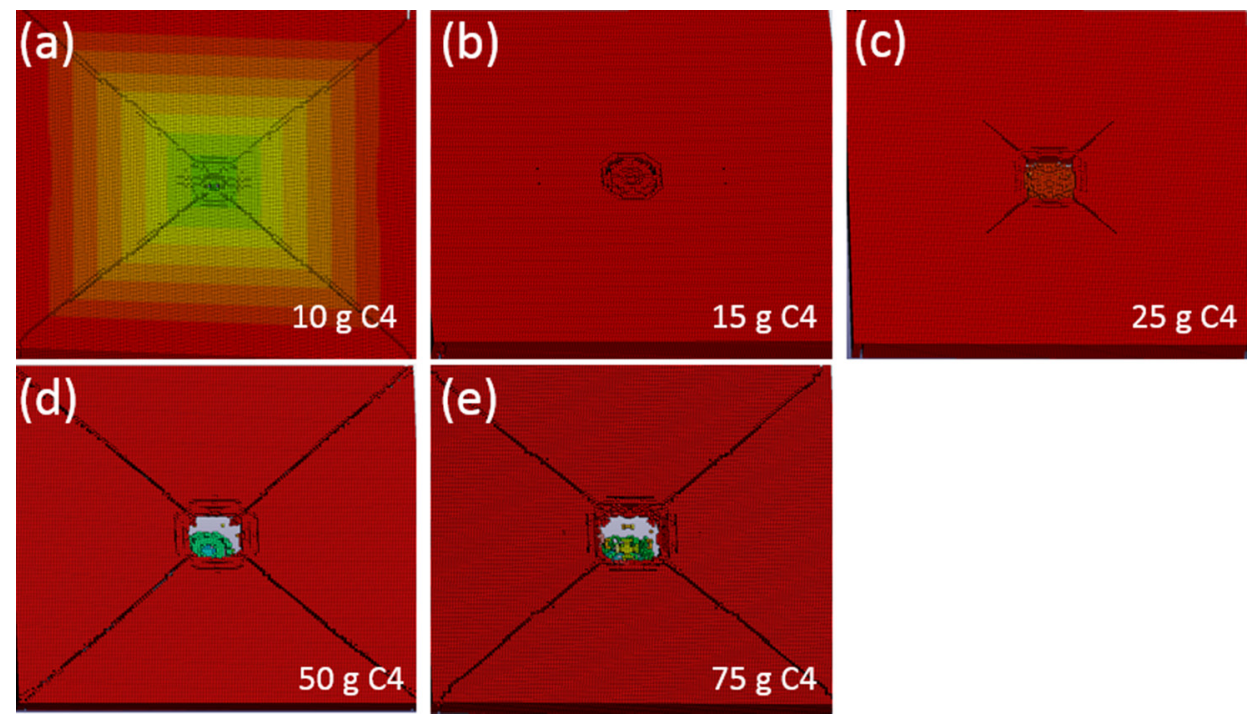

Figure 4: Damage at the front face.
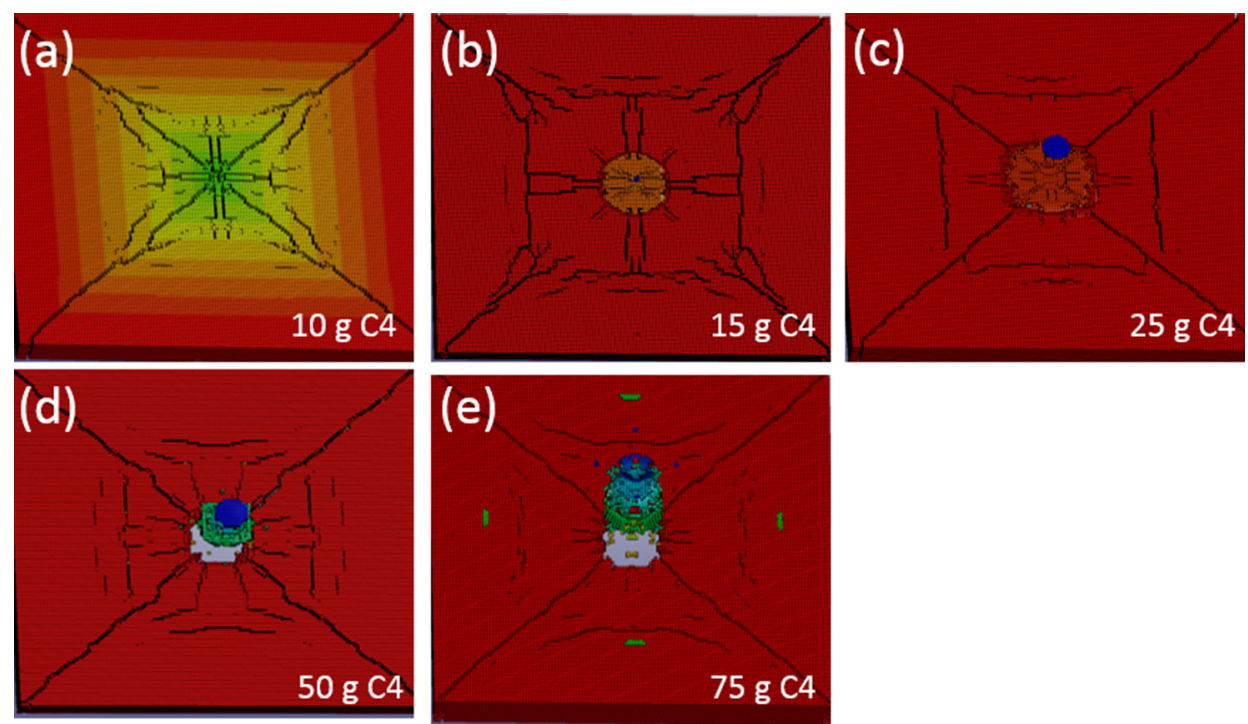

Figure 5: Damage at the back face.

with the formation of radial cracks that start from the centre of the slabs. The width of the cracks is approximately $5.5 \mathrm{~mm}$ for the 10 and $15 \mathrm{~g}$ while for the 25,50 and $70 \mathrm{~g}$ it is around $10 \mathrm{~mm}$.

\section{CONCLUSIONS}

Numerical simulations using the MM-ALE approach were carried out for five RC slabs under contact detonation of $75,50,25,15$ and $10 \mathrm{~g}$ of $\mathrm{C} 4$, in order to validate the experimental 
results obtained from the Royal Military Academy of Belgium. The numerical results are in favourable agreement with the experimental data, with average errors lying under $10 \%$. Furthermore, it was observed that the increase in the explosive amount leads to an increase of the damage from penetration to perforation. Based on this, it was concluded that the $25 \mathrm{~g}$ of $\mathrm{C} 4$ was the threshold of the total perforation of the concrete slabs. In addition, the crack propagation mode in the concrete slabs starts with flexure failure and continues with punching shear failure.

\section{REFERENCES}

[1] Ngo T., Mendis P., Gupta A. \& Ramsay J., Blast loading and blast effects on structures - an overview. Electronic Journal of Structural Engineering, 7, pp. 76-91, 2007.

[2] Tai, Y.S., Chu, T.L., Hu, H.T. \& Wu, J.Y., Dynamic response of a reinforced concrete slab subjected to air blast load. Theoretical and Applied Fracture Mechanics, 56, pp. 140-147, 2011. http://dx.doi.org/10.1016/j.tafmec.2011.11.002

[3] AUTODYN v4.2 user manual: Century Dynamics, Inc., 2001.

[4] LS-DYNA Keyword User's Manual, version 970 Livermore, California, USA: Livermore Software Technology Corporation, 2003.

[5] Zhou, X.Q., Kuznetsov, V.A., Hao, H. \& Waschl, J., Numerical prediction of concrete slab response to blast loading. International Journal of Impact Engineering, 35, pp. 1186-1200, 2008. http://dx.doi.org/10.1016/j.ijimpeng.2008.01.004

[6] Tu, Z.G. \& Lu, Y., Evaluation of typical concrete material models used in hydrocodes for high dynamic response simulations. International Journal of Impact Engineering, 36, pp. 132-146, 2009. http://dx.doi.org/10.1016/j.ijimpeng.2007.12.010

[7] McVay, M., "Spall damage of concrete structures," U.S. Army Corps of Engineers Waterways Experimental Station, 1988.

[8] Tabatabaei, Z.S. \& Volz, J.S., A comparison between three different blast methods in LS-DYNA: LBE, MM-ALE, Coupling of LBE and MM-ALE. Presented at the 12th International LS-DYNA Users Conference, Detroit, 2012.

[9] Zakrisson, B., Wikman, B. \& Häggblad, H.Å., Numerical simulations of blast loads and structural deformation from near-field explosions in air. International Journal of Impact Engineering, 38, pp. 597-612, 2011.

http://dx.doi.org/10.1016/j.ijimpeng.2011.02.005

[10] Schwer, L., Modeling rebar: the forgotten sister in reinforced concrete modeling. Presented at the 13th International LS-DYNA Users Conference, Detroit, 2014.

[11] Xu, K. \& Lu Y., Numerical simulation study of spallation in reinforced concrete plates subjected to blast loading. Computers \& Structures, 84, pp. 431-438, 2006. http://dx.doi.org/10.1016/j.compstruc.2005.09.029

[12] Luccioni, B. \& Araoz, G., Erosion criteria for frictional materials under blast loads. Mecánica Computacional,30, pp. 1809-1831, 2011.

[13] Broadhouse, B.J., The Winfrith concrete model in LS-DYNA3D, Structural Performance Department, AEA Technology, Winfrith Technology Centre, SPD/D(95)363, U.K1995.

[14] Ottosen N.S., A failure criterion for concrete. Journal of the Engineering Mechanics Division, 103, pp. 527-535, 1977. 